\title{
Avaliando reformas da gestão pública: uma perspectiva internacional ${ }^{*}$
}

\section{Introdução}

É uma honra ser convidado para coordenar esta edição especial sobre avaliação da modernização do setor público. No entanto, o convite feito pelo organizador foi algo como um cálice envenenado. Avaliar as reformas de gestão em todo o mundo é, por várias razões, uma tarefa quase impossível. É compreensível que ela tenha sido tentada, por tão poucas vezes, e geralmente por pessoas como políticos, consultores em gestão e gurus, que se sentem livres das inibições científicas da academia (ver, por exemplo, Dorrell, 1993).

Consideramos nossa tarefa, assim, duplicada. Naturalmente, faremos o melhor para completar a missão que nos foi dada pelo organizador: produzir uma "análise internacional comparativa". Antes disso, contudo, consideramos fundamental explicar por que tais comparações são tão difíceis e identificar alguns pontos importantes que devem acompanhar a leitura de um texto avaliativo como este. Assim, comecemos com os cinco conjuntos de problemas inter-relacionados que tanto dificultam a vida de um avaliador.

\section{Primeiro problema: as unidades de análise}

A simples frase "comparações internacionais" parece pressupor que Estados nacionais sejam a unidade de análise mais apropriada para uma avaliação das reformas de gestão pública. De certo modo, talvez o sejam. Alguns Estados-nação continuam sendo entidades distintas no mundo

Christopher Pollitt é $\mathrm{PhD}$ pela London School of Economics and Political Science e professor na Erasmus Universiteit Rotterdam, Holanda.

Geert Bouckaert é diretor do Instituut voor de Overheid da Katholiek Universiteit Leuven, Bélgica e membro do comitê de direção do European Group of Public

Administration (EGPA).

Contato: pollitt@fsw.eur.nl geert.bouckaert@ soc.kuleuven.ac.be Artigo publicado no International Journal of Political Studies no 3 de setembro 2001.

Traduzido por Maria Christiana Ervilha 
da gestão pública. Eles tendem a apresentar seus próprios sistemas político-administrativos, culturas administrativas etc., e parece-nos bastante natural que tais fatores influenciem significativamente a trajetória da reforma administrativa. Neste nosso estudo de dez países, encontramos fortes evidências das diferenças nacionais (Pollitt e Bouckaert, 2000) e estamos longe de sermos os únicos a concluir isso (ver, por exemplo, Christensen e Laegreid, 1998; Flynn e Strehl, 1996; Hood, 1996; Olsen e Peters, 1996; Premfors, 1998, Wollmann, 1997). A New Public Management - NPM (Nova Gestão Pública) pode ter afetado muitos países, mas, sem dúvida, afetou alguns muito mais do que outros. Além disso, mesmo aqueles que estão fortemente influenciados por ela tendem a adaptar seus "ingredientes" de forma quase individual, para produzir receitas nacionais diversas.

Tais diferenças são problemáticas porque, falando de modo coloquial, enfrentamos constantemente o perigo de comparar "maçãs e pêras". Países distintos têm diferentes pontos de partida, com histórias diversas, e seguem trajetórias distintas. A retórica comum sobre boa governança, eficiência, qualidade e confiança pode de fato esconder desfechos altamente pathdependent $^{1}$, nos quais uma combinação particular de prioridades, digamos, na Finlândia, é bastante distinta daquela da Austrália (para uma excelente abordagem geral sobre path dependence, ver Pierson, 2000; para uma visão das prioridades finlandesas em um contexto comparativo, ver Bouckaert, Ormond e Peters, 2000).

Para reduzirmos o perigo de comparar "maçãs e pêras" (esforço infrutífero, se os leitores me permitem o trocadilho), será preciso que sejamos mais específicos e detalhistas - e desçamos ao nível das comparações nacionais, tanto nas análises setoriais quanto nas comparações mais particulares de instrumentos ou processos individuais. Para os gerencialistas mais genéricos, a análise setorial pode parecer um tanto conservadora e estreita, mas para muitos profissionais do serviço público, estudos comparativos da prática dos seus campos de ação (saúde, educação, acompanhamento da liberdade condicional etc.) parecem acenar de forma mais promissora do que as panacéias prescritas pelos gurus da gestão pública. Tomando um exemplo recente, houve uma grande reorganização dos serviços de acompanhamento da liberdade condicional do Reino Unido logo após a revisão e síntese de uma pesquisa internacional sobre as taxas de reincidência criminal, associada às evidências da prática efetiva do serviço de acompanhamento da liberdade condicional local em todo o país (Inspetoria de Liberdade Condicional de Sua Majestade, 1998; ver também Furniss e Nutley, 2000). Infelizmente, porém, não podemos fornecer a visão ampla e confiável das avaliações setoriais. Nosso conhecimento limita-se a um ou dois setores. Assim, embora nossa impressão seja a de que as avaliações internacionais das reformas gerenciais, 
conduzidas de forma setorial, não sejam muito freqüentes, não temos

certeza de quantos trabalhos desse tipo têm sido realizados. Talvez exista mais material útil do que fomos capazes de localizar.

Analisando as avaliações de instrumentos e processos específicos, pode-se, por exemplo, comparar a introdução da Total Quality Management - TQM (Gestão de Qualidade Total) nos setores públicos dos Estados Unidos, Reino Unido e Suécia. Pode-se investigar as consequiências das tentativas de se introduzir um sistema de contabilidade gerencial na Finlândia, Nova Zelândia e Países Baixos. Ainda assim, problemas metodológicos poderão surgir. Muitas reformas, talvez a maioria delas, são amplamente "editadas" ou "traduzidas" quando transferidas de um contexto para outro (Sahlin-Andersson, 1996). Por exemplo, a TQM mostrou possuir uma identidade variável, que se adapta a diferentes ambientes (Joss e Kogan, 1995; Zbaracki, 1998). De maneira similar, reengenharia tornou-se um termo utilizado para cobrir uma grande variedade de mudanças, nenhuma delas radical como queriam os precursores do Business Process Re-engineering - BPR (Packwood, Pollitt e Roberts, 1998; Thompson, 2000). No entanto, podemos, ao menos, comparar diferentes tipos de "maçã". Infelizmente, ao que nos consta, existem pouquíssimas comparações internacionais do tipo "instrumento e processo". Esse é um enorme campo para futuras pesquisas acadêmicas. No momento, contudo, não podemos basear nossas comparações em tais trabalhos. Devemos nos ater aos Estados-nação como nossa unidade de comparação, apesar das limitações que essa escolha nos impõe.

\section{Segundo problema: as unidades de significado}

Os problemas vão além da simples comparação de entidades diferentes. A reforma da gestão pública não é somente uma questão de embaralhar peças de formatos diversos, como em um quebra-cabeças. As peças têm seus próprios significados, que variam de um país para outro (ou mesmo de um setor para outro). Por exemplo, no início dos anos 90, as agências executivas do Reino Unido eram freqüentemente vistas como o ápice dos progressos mais recentes. Elas representavam eficiência, especialização, ou seja, uma abordagem da gestão por desempenho. Porém, ao mesmo tempo, na Finlândia, as agências (conselhos nacionais) eram consideradas os remanescentes ultrapassados da burocracia legalista, orientada por procedimentos. Assim, enquanto o governo central do Reino Unido multiplicava rapidamente o número de suas agências, o governo central finlandês executava fusões, cortes e reduções gerais no quantitativo de agências (Pollitt et al., a ser lançado). 
Como no exemplo das agências da Finlândia e do Reino Unido, a reforma da gestão pública apresenta muitas vezes uma dimensão fortemente simbólica, o que traz problemas para a avaliação. As principais tendências neste campo têm mostrado uma propensão fortemente racionalista - quais são as metas, que evidência existe de que tenham sido atingidas etc. (ver, por exemplo, Shadish, Cook e Leviton, 1991). Assim, a maioria dos instrumentos convencionais de avaliação — análise de custobenefício, investigações quasi-experimentais, modelo econométrico, modelos comparativos (benchmarking) funcionais, entre outros fracassa ao tentar capturar o significado simbólico e retórico da reforma. Ainda assim, para os políticos — que são normalmente os que iniciam, ou ao menos facilitam as reformas — os efeitos retóricos e simbólicos de curto prazo são altamente importantes. Por exemplo, o Sr. Tony Blair já havia colhido ganhos políticos com relação aos seus oponentes ao enfatizar "a formulação de políticas públicas com base em evidências" e os atrativos de uma filosofia supostamente não-ideológica "das coisas que funcionam", muito antes que o real impacto de várias políticas pudesse ser analisado (Gabinete do Primeiro-Ministro, 2000; Davies, Nutley e Smith, 2000; Harrison, 1998). De forma mais geral, os aspectos retóricos e culturais parecem desempenhar um papel importante em várias reformas do setor público, e como até o momento têm sido negligenciados ou ignorados pelas abordagens convencionais de avaliação, nosso entendimento das causas e razões da reforma vem-se empobrecendo (Hood, 1998; Pollitt, 2001).

\section{Terceiro problema: a escassez de dados essenciais}

Comecemos com uma definição tradicional de que tipos de dados - e produzidos por quais métodos — seriam cientificamente exigidos para confirmar a eficácia das reformas do tipo NPM. O rigor puramente analítico exigiria algo semelhante para um teste clínico aleatório, com um grupo de controle, placebos, "avaliação duplamente cega"2 etc. (para os clássicos americanos e britânicos, ver Campbell e Stanley, 1963; Cochrane, 1972, respectivamente). Na vida real, no entanto, esse tipo de experimentalismo é raramente alcançado no campo da reforma gerencial. $\mathrm{O}$ "tratamento" não pode ser mantido em segredo, os placebos não podem ser considerados e, por uma combinação de razões éticas e práticas, grupos de controle confiáveis não podem ser formados. Sujeitar-se a procedimentos realmente experimentais é uma situação praticamente desconhecida para as reformas gerenciais.

Se nos tornarmos mais realistas, e relaxarmos nossas exigências metodológicas, poderemos pensar em termos de um estudo antes-e-depois. 
Primeiro, seria necessário dispormos de um quadro bastante exato do status

quo ante. Isso incluiria dados quantitativos relativos aos critérios-chave pelos quais pretendemos julgar a reforma, isto é, custo, eficiência técnica, qualidade do serviço ou outros (a questão dos critérios é discutida posteriormente). Em segundo lugar, precisaríamos de uma descrição igualmente exata da situação mundial depois que a reforma tivesse sido implementada. Em terceiro lugar, deveríamos ser capazes de predizer qual seria a situação mundial caso a reforma não tivesse acontecido e o sistema preexistente tivesse continuado (ou seja, um “contrafactual” — ver Elster, 1978). Dentro desse esquema, compararíamos nossa segunda descrição tanto com o contrafactual quanto com o status quo ante. As diferenças entre a situação com reforma e o contrafactual nos dariam a exata medida do impacto da reforma (Pawson e Tilley, 1997).

Infelizmente, mesmo essa abordagem menos exigente está um tanto além de qualquer análise que os governos tenham realmente conduzido. A NPM continua intocada por essas avaliações "científicas" tradicionais. Porém, algumas investigações menos rigorosas efetivamente aconteceram. Em 1995, um de nós revisou algumas avaliações de amplo escopo sobre as reformas da gestão do setor público e as achamos um tanto limitadas (Pollitt, 1995). Desde então, a situação teve uma pequena melhora, mas certamente não se modificou. Ainda se vê muitos (provavelmente a maioria) dos grandes programas de reforma serem anunciados e implementados sem que nenhum plano de avaliação sistemática e independente seja apresentado. Alguns, como os neozelandeses em 1991, e a Comissão Européia, com respeito às suas reformas (MAP, 2000), incluíram uma avaliação quando a reforma estava a caminho - uma atitude que é, sem dúvida, melhor do que nada, mas que geralmente impede o estabelecimento de linhas de base confiáveis para comparação entre antes e depois. Um dos reformistas mais radicais - o Reino Unido - elaborou poucas análises sérias durante os conturbados dias da reforma entre 1987 e 1997, embora o governo trabalhista tenha lançado várias avaliações desde então. Os australianos e neozelandeses tentaram realizar grandes avaliações, e os americanos organizaram uma série de avaliações em torno da National Performance Review - NPR (Revisão Nacional de Desempenho) de 1993 e do Government Performance and Results Act — GPRA (Lei Governamental de Desempenho e Resultados) de 1992. Os finlandeses também organizaram uma série de avaliações das suas reformas no final dos anos 80 e início dos anos 90 (Holkeri e Summa, 1996). No entanto, apesar das diversas reformas realizadas durante os anos 80 e início dos 90, aparentemente nenhuma avaliação independente de amplo escopo ocorreu, por exemplo, no Canadá, França, Holanda, Suécia ou Reino Unido.

Mesmo onde houve avaliações sérias, os dados exigidos para um julgamento confiável sobre alguns dos grandes temas eram freqüentemente 
inacessíveis. Por exemplo, nem a enorme avaliação australiana do final dos anos 80, nem a revisão neozelandesa de 1991 conseguiram estimar o custo total dos programas de reforma ou a economia deles resultante (Conselho Consultivo Gerencial, 1989; Grupo Consultivo, 1991). O estudo da Nova Zelândia também destacou "não existirem dados confiáveis que possibilitem a comparação da produtividade do serviço público no período da introdução das reformas" (Grupo Consultivo, 1991: 26). Com relação ao teste padrão-ouro ${ }^{3}$ — impactos finais (resultados) — em geral, estes são tão difíceis de mensurar quanto de serem atribuídos a causas particulares. Se as notas dadas pelos cidadãos aos governos melhoraram, terá sido por causa da reforma ou da recuperação da economia? Se as queixas aumentaram, isso se deve à má qualidade dos serviços ou à melhoria do sistema de coleta de reclamações? Se o serviço de empregos deixou de atingir sua meta de alocar a mão-de-obra desempregada há muito tempo, é por que foi ineficiente ou por que a economia piorou e os empregadores simplesmente deixaram de contratar? Construir contrafactuais convincentes (cenários para o que teria acontecido se a reforma não tivesse sido implementada) é uma arte difícil e raramente praticada.

\section{Quarto problema: os critérios múltiplos}

Se tivermos que chegar a um julgamento com relação aos efeitos das reformas baseadas na $N P M$, os dados disponíveis deverão sujeitar-se a um conjunto de critérios. Mas quais seriam eles? Os documentos oficiais geralmente são vagos a esse respeito, seja falhando ao definir termoschave como "produtividade" ou "qualidade", seja mencionando toda uma série de critérios sem explicar como eles devem ser conciliados uns com os outros, ou, quando necessário, substituídos uns pelos outros (ver Pollitt e Bouckaert, 2000, capítulo 7). Não podemos fazer muito, além de indicar brevemente quais parecem ser os critérios mais comuns em uso, e dizer algo sobre como eles devem ser definidos e medidos.

Um primeiro critério é a economia, entendido como uma redução nos insumos. Os governos gostam dessa idéia, visto que ela os ajuda a demonstrar que não estão desperdiçando o dinheiro dos contribuintes e que têm a administração pública "sob controle". Além disso, "economia" soa como uma noção simples, facilmente compreendida pelo cidadão comum. Na verdade, porém, “economia” não é um tema muito exato. Ela pode ter vários sentidos técnicos diferentes; por exemplo, uma redução absoluta no gasto comparada com o período prévio, uma redução abaixo do nível de gasto inicialmente previsto, uma redução em custos unitários, 
entre outros (ver Pollitt e Bouckaert, 2000: 100-101). Além disso, é preciso estar sempre atento para o caso de a economia em um local ter sido atingida, em parte ou inteiramente, por causa da transferência do gasto para outro (como em muitos programas de descentralização, em que o governo central transfere a responsabilidade por determinados programas para níveis subnacionais do governo). Por último, é claro, a economia pode ser totalmente genuína, mas pode causar efeitos negativos em outros critérios, como produtos (menor eficiência) ou resultados (menor eficácia).

Um segundo critério seria o de processos melhores - serviços mais rápidos, one-stop shops ${ }^{4}$ que tornam o acesso mais conveniente ao público, melhor "atenção ao cliente" na forma de funcionários mais simpáticos e bem capacitados, entre outros (Bouckaert, 2001). Alguns dos artigos das Declarações do Cidadão, introduzidas na Bélgica, Finlândia, França, Itália, Portugal e Reino Unido, são desse tipo (ver, por exemplo, Bouckaert, 1995; Pollitt, 1994 e Schiavo, 2000). Existem também vários concursos nacionais e internacionais de qualidade de serviço, que avaliam as melhorias nesse campo (ver, por exemplo, Loeffler, 1995 e Borins, 1998). Medidas específicas para melhoria dos processos podem ser razoavelmente claras, mas seu significado mais amplo não é necessariamente tão exato. Por exemplo, solicitações de benefícios podem ser processadas com mais rapidez, mas a custo de mais erros. Tratamentos hospitalares para determinadas doenças podem ser fornecidos de maneira mais ágil e flexível, mas sem nenhum efeito nos resultados da situação de saúde (ou seja, processos melhoram, mas os resultados permanecem os mesmos).

Como terceiro critério, pode-se buscar maior eficiência em função das reformas (definindo-se eficiência como a razão insumo/produto). Seguramente, "eficiência" tem sido um termo muito utilizado no mundo anglófono (Pollitt, 1993). Além do mais, já houve muitas tentativas para se medir as mudanças na eficiência (por exemplo, Departamento de Orçamento, 1997; Chancelaria do Ducado de Lancaster, 1997). Apesar de ser, de fato, uma medida útil, principalmente se fizer parte de uma série temporal, a eficiência possui algumas limitações. Assim como a melhoria nos processos, os benefícios da eficiência podem não levar a melhores resultados — de fato, a eficiência pode, às vezes, ser aumentada às custas de uma queda na eficácia. Por exemplo, se a razão de estudantes aumentar nos estabelecimentos de ensino de forma que professores ensinem a mais alunos e trabalhem mais intensivamente, o nível geral de aprendizado poderá declinar, visto que a quantidade e qualidade de atenção dedicada a cada criança será menor e os professores estarão mais sobrecarregados e menos instrumentalizados na sua abordagem.

O quarto critério é o que muitos consideram como o teste "padrãoouro" - isto é, se a eficácia dos programas públicos melhorou. Eficácia 
aqui é definida como o impacto do programa no mundo externo, em relação aos seus objetivos originais (razão objetivos/resultados). O novo tratamento melhora o estado de saúde dos pacientes? O novo sistema escolar melhora o nível educacional dos alunos? A nova estratégia de policiamento reduz realmente o crime? O novo benefício familiar reduz a pobreza? Eficácia é um critério muito poderoso, mas geralmente difícil de se aplicar nas reformas de gestão. Parte do problema é o longo intervalo de tempo, pois uma reforma administrativa de grande escala pode durar três anos ou mais, e podem-se passar muitos anos até que seja possível comparar os resultados do programa com o status quo ante. Outra parte do problema é a complexidade. Ou seja, mesmo quando os resultados podem ser medidos, quanto se pode atribuir a um programa particular e não a outros fatores?

Um quinto critério, apontado por alguns defensores das reformas como um objetivo importante, é a melhoria na capacidade dos sistemas administrativos. Como o mundo vem se tornando cada vez mais complexo, com os fatos acontecendo de forma cada vez mais rápida, o sistema da administração pública precisa adaptar-se a essas novas condições. Embora isso seja absolutamente verdadeiro, este é um critério de difícil operacionalização. Como podemos medir a capacidade de um sistema? Como podemos comparar a capacidade de um sistema em dois ou mais Estados? Os governos têm contribuído muito pouco, até o momento, para que compreendamos como fazê-lo.

Por último, a retórica da reforma parece utilizar tipos ideais como critério para o seu sucesso. Por exemplo, determinadas medidas justificamse caso a intenção seja tornar o governo menor, ou mais descentralizado, ou mais próximo dos setores empresarial e voluntário. Por detrás dessa retórica está a visão de tipos ideais de sistema — "enxutos", "próximos do cidadão", "em parceira” etc. O "sucesso" de uma reforma é definido em termos do quanto ela aproxima os sistemas existentes de um ou mais desses Estados ideais. Esse tipo de critério ideológico ou doutrinário é, muitas vezes, difícil de se operacionalizar ou aplicar. Mesmo quando é possível, a relação entre o "sistema ideal" e os outros critérios de sucesso (ver acima) pode ser um tanto ambígua. Um sistema descentralizado é sempre mais eficaz? Um governo menor será sempre um governo melhor? Os projetos realizados em parceria com o setor privado serão sempre mais baratos e bem-sucedidos? Está claro que as respostas a cada uma dessas questões é "não, nem sempre, depende". Mesmo assim, essa complicação não impede os líderes das reformas de utilizar a retórica da descentralização, parceria etc., o que gera, evidentemente, rendimentos próprios (Pollitt, 2001).

Assim, mesmo que tenhamos mais e melhores dados, o tema da avaliação de reformas ainda será complexo. Os critérios são múltiplos e 
interligados, e ao se dar maior importância a um, pode-se estar comprometendo a performance do outro. Grupos diferentes poderão ter pontos de vista diferentes e perfeitamente legítimos com relação a determinados critérios, priorizando um ou outro em um dado momento ou lugar. De fato, a complexidade percebida aqui aumenta quando se trata do paradigma da NPM. Todos os critérios discutidos acima foram retirados da retórica dos próprios reformadores. Se permanecemos do lado de fora do paradigma - por exemplo, para analisar critérios como eqüidade, gênero, confiança, lealdade ou cumprimento da lei — o desafio da avaliação da NPM tornase formidável. Exemplos de tentativas interessantes incluem um estudo britânico sobre como o concurso compulsório, mesmo tendo aumentado a eficiência, teria degradado as políticas de oportunidades iguais de emprego (Escott e Whitfield, 1995), e uma análise que indica que os valores solidários da sociedade sueca estão em declínio, e que a crescente disponibilidade de alternativas para a saída dos serviços públicos pode ter colaborado com o aumento das desigualdades sociais (Micheletti, 2000).

\section{Quinto problema: o caráter evasivo (imponderável) da mudança}

A mera existência de atividade intensa não implica necessariamente impacto maior. Tampouco o excesso de conversa implica muita atividade. $\mathrm{Na}$ avaliação de reformas de gestão, é importante separar o discurso em favor da reforma da decisão real de reformar, e, então, verificar cuidadosamente se as decisões foram realmente implementadas como novas práticas. Por último, é preciso questionar se as novas práticas realmente mudaram os resultados (Pollitt, 2001). As reformas podem tender para a paralisia, ou desviar-se do seu curso, em qualquer ponto da seqüência "discussão — decisão — prática — impacto". Podem existir vantagens em se dizer uma coisa e fazer outra (Brunsson, 1989).

Além disso, mesmo quando elas alcançam o estado de prática real, a observação de um elemento particular pode levar a equívocos. A coerência entre as reformas não está, de modo algum, garantida. Uma nova prática pode contradizer outra, ou podem faltar componentes vitais. Contratos ligados ao desempenho podem ser introduzidos sem um sistema adequado de mensuração para garanti-los. Auditorias externas podem ser reformadas enquanto as auditorias internas mantêm-se conservadoras, ou são, por vezes, inexistentes. Um orçamento anual de três anos pode ser introduzido, mas sem a estabilidade de recursos necessária para que ele funcione como previsto.

A observação dos diferentes estágios pelos quais passa uma reforma pode levar-nos a afirmar que a retórica da mudança é um tanto acessível. 
"Falar é fácil", diz o ditado. Freqüentemente, informações sobre as decisões relativas a reforma são fáceis de se obter; os governos gostam de dar certa proeminência às suas decisões. Já as informações sobre mudanças na prática — a implementação da reforma — são, em geral, mais difíceis de se encontrar. É claro que alguns estudos de caso indicam melhoria nos processos. Em vários países (mas não em todos) alguns dos importantes requerimentos diários, tais como carteiras de habilitação, carteiras de identidade, passaportes e formulários de impostos, são encontrados muito mais facilmente do que há 15 anos. Encontramos também volumes de dados sobre a melhoria no tempo de resposta - espera em salas de emergência nos hospitais, processamento de solicitações de benefícios, inspeções em postos de alfândega e muitos outros (ver, por exemplo, Chancelaria do Ducado de Lancaster, 1997). Até o aumento da precisão na previsão do tempo pode ser apresentado como melhoria (Escritório de Auditoria Nacional, 1995). Porém, ao menos duas qualificações importantes precisam ser feitas. Primeiro, é quase certo que exista um viés na tarefa de relatar: os sucessos são celebrados e os fracassos são maquiados ou simplesmente omitidos. Não é comum que políticos e servidores públicos participem de conferências para contar como suas reformas fracassaram. Em segundo lugar, o que o processamento da informação freqüentemente não mostra é quando algumas partes (ocultas) do sistema pagaram o preço da melhoria de outras partes do mesmo; por exemplo, se a meta de processar $\mathrm{x} \%$ das solicitações de benefício dentro de um determinado período de tempo é atingida, mas aqueles poucos casos mais complexos pagam o preço de esperar mais tempo do que antes (ver Escritório de Auditoria Nacional, 1998).

Em último lugar, mas não menos importante, a informação a respeito dos resultados (principalmente os resultados finais) é normalmente inexistente, ou difícil de se encontrar.

\section{Visão geral}

Estamos chegando ao ponto em que começamos a levar em consideração os "resultados" da reforma. Entretanto, antes de nos lançarmos às especificidades do tema, é necessária uma certa descrição do cenário. Sem determinadas indicações dos problemas que as reformas deveriam solucionar, é muito difícil avaliá-las. Nesta seção, portanto, identificaremos alguns dos principais motivos da reforma, e, muito brevemente, esboçaremos os tipos de atividades realizadas (para uma descrição mais detalhada, ver Pollitt e Bouckaert, 2000, anexo especial).

Em termos gerais, os motivos para a reforma têm se originado em 
variado com o tempo e de acordo com as circunstâncias e os pontos de partida particulares de cada um. Um forte motivo - principalmente durante os períodos de crise econômica do início dos anos 80 e 90 - foi simplesmente o de economizar. A história é bem conhecida. Muitos governos enfrentaram um movimento de "tesoura" dos crescentes custos de bemestar social face às decrescentes possibilidades da criação de novos impostos. Cortar o gasto público, ou ao menos reduzir sua taxa de crescimento, tem estado em alta na agenda política.

Em segundo lugar, houve um amplo desejo de remediar o fraco desempenho percebido em áreas significativas do setor público. À medida que se elevam os padrões de educação, uma crescente parte da população acostuma-se com padrões mais altos de serviço no setor privado, e tornase cada vez menos inclinada a aceitar respostas inflexíveis e burocráticas dos serviços públicos. Assim, tanto a qualidade do serviço quanto o aumento da produtividade têm sido metas amplamente defendidas. Alguns políticos e servidores públicos crêem que tais melhorias também ajudarão os governos a reverter os níveis decrescentes de confiança dos cidadãos (e, portanto, da legitimidade do governo), fato que vários estudos parecem demonstrar em toda a Europa Ocidental e América do Norte.

Em terceiro, à medida que as reformas para economizar e melhorar o desempenho foram iniciadas, ficou visível que algumas mudanças poderiam alterar o padrão de responsabilidade de diferentes atores políticos e administrativos. Vários países começaram a pesquisar novos mecanismos de accountability pública (por exemplo, Sharman, 2001) e outros sentiramse obrigados a reconsiderar a questão da proteção e melhoria dos padrões da vida pública (por exemplo, SIGMA, 1999).

Passemos agora a um breve histórico das mudanças. Em geral, as reformas gerenciais apresentaram um volume e variedade realmente grandes. É bastante provável que o processo de reforma tenha se intensificado após 1985 , e que os contatos internacionais tenham desempenhado um papel importante no "mercado" global de determinados tipos de reforma (Pollitt e Bouckaert, 2000).

A intensidade das reformas variou consideravelmente de um país para outro. Alguns países (Austrália, Estados Unidos, Nova Zelândia e Reino Unido) foram extremamente ativos. A uma reforma seguiu-se outra em uma sequiência quase atordoadora (ver, por exemplo, Boston et al., 1996; Pollitt e Bouckaert, 2000; Savoie, 1994). Esses são os países que lideraram a NPM e a "reinvenção" (Kettl, 2000). Um segundo grupo de países também esteve ocupado com a reforma administrativa, mas de maneira menos radical (e, de certo modo, menos exibicionista) que o primeiro grupo. Esses "modernizadores" têm se mostrado menos iconoclastas, menos doutrinários e menos seduzidos pela privatização, 
gestão por contrato e pelas maravilhas dos mecanismos de mercado que o primeiro grupo. Eles incluem a França, os países nórdicos, os Países Baixos e o Canadá (ver, por exemplo, Guyomarch, 1998; Kickert, 2000). Um terceiro grupo foi - devido a uma série de razões - muito mais cuidadoso (ou inibido). Membros proeminentes desse grupo são a Alemanha e o Japão, embora deva-se ressalvar que uma boa dose de reforma aconteceu na Alemanha, em nível local, e que, desde o final dos anos 90, o Japão começou a desenvolver programas de mudança com alguma influência da NPM (Derlien, 1998; Wollmann, 1997).

Em quarto lugar, devemos mencionar o mundo em desenvolvimento e os Estados em transição da Europa Central e Oriental (Bouckaert e Timsit, 2000). Muitos desses países tentaram implementar um ou outro elemento da NPM, com níveis variados de sucesso. Em vários desses casos, as reformas foram cobradas por organizações internacionais tais como o Banco Mundial, SIGMA ou a Comissão Européia, ou por mentores ex-colonialistas, tais como o Departamento para o Desenvolvimento Internacional do Reino Unido. Podemos pensar nos programas de criação de agências executivas em locais bastante distantes uns dos outros, como a Tanzânia, a Jamaica e a Látvia. No presente momento, há indícios de que alguns desses países (e mesmo alguns organismos internacionais) começam a lamentar certos aspectos do processo. $\mathrm{Na}$ Látvia, por exemplo, algumas medidas agora vêm sendo tomadas para controlar as mais de 150 agências que proliferaram durante os anos 90. Está claro que os mecanismos de controle e accountability vigentes são inadequados, e que uma grande proporção do orçamento nacional está reservada para agências que estão muito além do controle de seus ministérios de origem.

Uma maneira de classificar os esforços de reforma é pensar em termos das quatro principais estratégicas que qualquer um pode usar. Elas são:

- manter: conservar a máquina administrativa tal como ela é, mas ajustar e equilibrar sempre que possível;

- modernizar: realizar as mudanças mais fundamentais nas estruturas e processos, por exemplo, mudando a orientação do processo orçamentário de insumo para produto; criando novos tipos de organização do setor público, como agências autônomas; modificando o contrato de trabalho dos servidores públicos etc.;

- mercantilizar: introduzir mecanismos de mercado (Market-Type Mechanisms - MTMs) no setor público, acreditando que eles vão gerar eficiência e melhor desempenho (OCDE, 1993). Por exemplo, no Reino Unido, os governos conservadores dos anos 90 introduziram um "mercado interno" para o Serviço Nacional de Saúde, de modo que os hospitais tivessem que competir pelos pacientes em termos de preço e qualidade dos serviços. Dessa forma, as atividades continuam dentro do setor estatal, 
mas as organizações estatais são obrigadas a se comportar cada vez mais como empresas do setor privado; e

- minimizar: reduzir o setor estatal tanto quanto possível, fazendo o máximo uso da privatização e da contratação externa. Os ativos públicos são vendidos, e as atividades anteriormente desempenhadas por servidores públicos são oferecidas aos setores comerciais e voluntários. Essa estratégia reflete a atitude pessimista com relação ao potencial do setor público para a boa gestão e a legitimidade da propriedade estatal.

Em termos gerais, os países "anglo-saxões" (Austrália, Estados Unidos, Nova Zelândia e Reino Unido) foram além e mais rápido pelos dois últimos caminhos (mercantilizar e minimizar) do que a maioria dos países da Europa continental. Por razões óbvias, ambas estratégias tendem a criar maior resistência por parte das organizações do setor público e sindicatos. Assim, a mercantilização e a minimização são não apenas mais radicais, como também mais conflituosas do que a manutenção e a modernização. Os ganhos possíveis são divulgados — por seus proponentes como maiores, mas os riscos de fracasso e de resistência são significativamente altos. Os países da Europa continental preferiram um impulso central rumo à modernização, temperado com uma pitada ocasional de mercantilização e privatização.

Não escapará da atenção do leitor o fato de nosso mapa global possuir enormes lacunas. Os países mediterrâneos, a América do Sul, a maior parte da Ásia e outros territórios não foram sequer mencionados. A razão é simples: não sabemos o bastante para dizermos qualquer coisa. Esperamos que um dos maiores feitos desta edição especial seja diminuir a enorme ignorância dos países da $N P M$ acerca do que tem acontecido nessas partes do mundo.

\section{Resultados}

Após descrever todas as dificuldades, finalmente chegamos de volta à questão original: quais foram os resultados das reformas gerenciais, partindo de uma perspectiva comparativa? Dados os problemas discutidos acima, esperamos que os leitores entendam por que o que dissermos aqui será tanto incompleto quanto coroado de qualificações. Apesar disso, esperamos que tais reflexões preparem o terreno para os trabalhos mais detalhados constantes desta edição especial, e talvez encorajem outros acadêmicos a identificar outras avaliações úteis que tenhamos ignorado, e/ou a publicarem novas avaliações eles mesmos.

Primeiramente, consideremos as evidências com respeito a economia e redução do tamanho dos governos - provavelmente, as duas metas mais proeminentes de vários países quando o movimento internacional da reforma foi lançado nos anos 80. À primeira vista, os resultados parecem 
ser positivos: "muitas das nações que realizaram esforços de reforma mais agressivos notaram reduções no gasto governamental como uma parcela da economia realizada durante os anos 90 , além do pagamento de salários dos funcionários governamentais ter caído mais nas nações engajadas nas reformas mais agressivas" (Kettl, 2000, p.52 e 53 — ver original para quadros e gráficos detalhados, baseados, na maioria, no banco de dados da OCDE). Além disso, os reformistas mais vigorosos foram capazes de registrar reduções substanciais no número de "burocratas". A Sra. Thatcher reduziu o serviço público não-industrial em mais de $20 \%$. O NPR do vicepresidente $\mathrm{Al}$ Gore tinha reduzido a força de trabalho federal americana em 299.600 postos (13,9\%) até o final do ano de 1998 (Maas e van Niespen, 1999). Uma revisão interna das reformas de gestão financeira da Nova Zelândia concluiu que o "aparato (pós-reforma) era um instrumento eficaz para controlar e reduzir os gastos do governo central" - embora ela também tenha destacado que os efeitos dos novos instrumentos e prioridades do novo governo não poderiam ser separados uns dos outros (Brumby et al., 1996). No Canadá, as reformas dos anos 90 permitiram que se alcançasse o primeiro equilíbrio orçamentário em três décadas (1997-1998, ver Aucoin e Savoie, 1998).

Uma inspeção mais cuidadosa desses "resultados" não destrói inteiramente a correlação entre reforma e economia/downsizing, mas introduz dúvidas e ambigüidades consideráveis. Obviamente, é preciso admitir que os cálculos de proporções como gasto público/PIB são determinados tanto pelas taxas de crescimento econômico quanto pelas mudanças no gasto governamental. Em geral, o período 1990-2000 foi de forte crescimento econômico, portanto a proporção relativa ao gasto governamental teria diminuído se o valor absoluto do gasto tivesse se mantido no mesmo patamar ou crescido devagar. Isso deve explicar por que a Irlanda, um país que nunca foi um líder nas reformas da $N P M$, venha na frente da Nova Zelândia e do Reino Unido em termos de reduções de despesas governamentais como percentual da tabela do PIB. Se analisássemos um período de tempo diverso - digamos o início dos anos 80 , ou o começo da década de 90 , quando o crescimento era lento ou negativo - um resultado bastante diferente poderia ser obtido.

Uma questão de interpretação ainda mais séria é a direção da causalidade. Seria pouco seguro simplesmente pressupor que a queda do percentual dos gastos governamentais em relação ao PIB teria sempre resultado das reformas da $N P M$. De forma contrária, a queda poderia advir dos mais tradicionais tipos de corte de despesas. Um estudo sueco concluiu justamente isso - que as reduções de despesas tendiam a estimular as reformas gerenciais, e não o contrário (Murray, 1998).

Além de tudo, temos todo o direito de ser cuidadosos com alegações tais como "o número de servidores públicos foi reduzido em tantos por 
cento". Freqüentemente, essas manchetes escondem situações mais complexas, em que as tarefas são transferidas para outras organizações do setor público (autoridades locais, quangos ${ }^{5}$ ), cujos quadros funcionais aumentaram (para o caso sueco, ver, por exemplo, Micheletti, 2000). Uma alternativa é que mais tarefas tenham sido contratadas externamente, de modo que os custos dos serviços do Estado de bem-estar sejam executados por empresas com fins lucrativos, como é cada vez mais o caso na Austrália, Estados Unidos e Reino Unido (para o caso americano, ver Peterson, 2000). Nesse exemplo, o "governo" está menor em termos de pessoas, mas não em termos de responsabilidades.

Por último, precisamos perceber que a correlação entre reformas "agressivas" e economia/downsizing, embora substancial, está longe de ser completa. As cifras da OCDE contêm algumas aparentes anormalidades. Consideremos a mudança da proporção entre gasto governamental e PIB. Nessa medida, a Grécia vem bem "na frente" do Reino Unido, e a Bélgica consideravelmente "na frente" da Austrália. Pode-se somente concluir que, obviamente, algo mais acontece, além da NPM. Um acadêmico proeminente, apesar de ser normalmente otimista a respeito do impacto das reformas gerenciais, concorda que, além do banco de dados da OCDE, "faltam dados bons e confiáveis disponíveis em qualquer país, com relação à economia produzida pela reforma" (Kettl, 2000: 51).

O segundo critério avaliativo foi o da melhoria dos processos. Nesse caso, foi fácil encontrar exemplos de sucesso, mas difícil descrever o panorama geral. A literatura que trata os casos e anedotas da melhoria dos processos é extensa (por exemplo, Borins, 1998; Consulado do Ducado de Lancaster, 1997; Gore, 1996; Osborne e Gaebler, 1992; e muitos mais). O problema, como afirmado anteriormente, reside em parte na possibilidade de que estejamos lidando com uma seleção tendenciosa. Há outra literatura, menor e menos importuna, que conta uma história diferente. Por exemplo, Packwood et al. (1998) mostram como o imenso e caro esforço de reengenharia em um grande hospital britânico ficou bem aquém das suas expectativas originais. Thompson (2000) descreve um projeto ainda maior de reengenharia na Administração do Social Security Administration (SSA) americano. Depois de cinco anos de esforços, o projeto fracassou em cumprir quase todas as suas metas e o SSA não o classifica mais como "reengenharia clássica". Da mesma forma, o Departamento de Serviço Social do Reino Unido gastou boa parte dos anos 80 e do início da década de 90 implementando uma nova e grandiosa "Estratégia Operacional", mas nem a economia estimada nem a melhoria nos serviços projetada conseguiram se materializar (Gabinete Nacional de Auditoria, 1999: 25). Portanto, existem, definitivamente, alguns sucessos e alguns fracassos. A incidência relativa desses resultados contrastantes não é conhecida em qualquer país. Tampouco dispomos de um modelo 
claro e confiável do que poderiam ser as diferenças contextuais cruciais entre sucesso e fracasso (sobre essa necessidade, ver Pawson e Tilley, 1997).

Vários dos comentários sobre a melhoria nos processos também se aplicam à análise da eficiência. Nesse caso, há também muitos exemplos de ganhos de produtividade (Consulado do Ducado de Lancaster, 1997), mas considerável dificuldade na interpretação da validade e confiabilidade de muitos dos dados quantitativos. Gabinetes Nacionais de Auditoria de vários países (inter alia, Estados Unidos, Suécia e Reino Unido) buscaram desempenhar um novo papel e validar a onda de indicadores de desempenho que agora jorram do governo executivo. Novamente, em termos genéricos, fica claro que a aplicação das técnicas da NPM por vezes produz um considerável aumento na eficiência, mas em outras ocasiões encontramos desapontamentos e até perversões (Pollitt, 2000; Smith, 1996). Começamos a ter alguma idéia de quais podem ser os principais fatores de risco, mas identificá-los e atribuir-lhes peso em contextos específicos ainda é mais um exercício de magia do que de ciência.

A eficácia foi nosso quarto critério. A conceitualização dos resultados finais da reforma gerencial é menos simples neste caso do que no de outros programas, como redução da pobreza ou cuidados de saúde. Medilos também é difícil. Em um mundo ideal, o reformista deveria torcer por uma mudança cultural no serviço público que iria incluir valores tais como compreensão, qualidade, eficiência, entre outros. Mas como poderá um observador independente verificar em que medida tais coisas realmente aconteceram, e em que medida elas se deveram especificamente à reforma, e não a outras influências contemporâneas? Um número bastante pequeno de estudos aborda o tema com algum grau de sofisticação. Um bom exemplo é a análise de Thompson sobre a NPR americana. Ele conclui que, apesar de tudo que foi alcançado, "poucos objetivos hierárquicos mais altos da NPR foram cumpridos de maneira sistemática" (Thompson, 2000: 508).

O quinto e sexto critérios são de ordem sistêmica. Um era a produção de um sistema mais flexível, mais capaz de adaptar-se diante da mudança. O outro era o movimento rumo a um Estado ideal, enxuto, descentralizado e empresarial, segundo o modelo da NPM. Como observado anteriormente, é praticamente impossível operacionalizar qualquer um desses critérios na forma de uma ou duas medidas simples. Possivelmente, o melhor a fazer seja anotar as impressões contidas nos grandes trabalhos de síntese preparados por especialistas nacionais. Começando com a Nova Zelândia, a avaliação de 1991 concluiu que existiam benefícios "substanciais" em termos da capacidade do sistema (Grupo Consultivo, 1991: 11). Escrevendo algum tempo depois, Boston et al. (1996) reconhecem a extraordinária escala e qualidade das mudanças naquele pequeno país, mas também apontou os negócios inacabados e 
tensões contínuas entre objetivos divergentes. O Reino Unido foi outro líder da reforma. O que fica claro da experiência britânica é que a reforma não tem fim. Após 15 longos anos de intensa reforma gerencial, o novo governo trabalhista de Tony Blair publicou um documento estratégico (White Paper) ressaltando a necessidade de mais mensuração, mais desenho de metas, mais avaliação, mais tecnologia da informação, mais mudança cultural para o servidor público (desta vez para que ele possa ficar à vontade com a maneira "articulada" de trabalhar "em rede" Davies, Nutley e Smith, 2000; Gabinete do Primeiro Ministro, 1999). É evidente que apesar de toda uma geração de $N P M$, o ideal continua de certa forma distante. Nos Países Baixos a mudança foi menos apressada - e provavelmente menos profunda. Kickert (2001) conclui que:

"Todas as tentativas políticas de uma renovação mais fundamental do Estado e da administração fracassaram. A democracia consensual holandesa, com suas deliberações infindáveis e eterna busca de compromisso e consenso, reafirma que as mudanças revolucionárias nunca ocorrerão".

Na França, as sucessivas ondas de reforma administrativa certamente trouxeram mudanças, mas os elementos de continuidade (tais como a centralização dos grands corps e seu tipo particular de profissionalização tecnocrata, ou a força política dos sindicatos do serviço público) são, no mínimo, tão notáveis quanto os da mudança (Guyomarch, 1999; Rouban, 1995). No Canadá, oito anos de mudança sob a égide do primeiro-ministro Mulroney não produziram direcionamentos ou modelos consistentes, e muito do tão propalado programa Public Service 2000 parece ter fracassado (Auditor-Geral do Canadá, 1993; Savoie, 1994). A reforma pós-1993 parece mais bem-sucedida, mas também, de certa forma, mais tradicional (Aucoin e Savoie, 1998). E não é surpresa que o sistema norueguês pareça ter-se mostrado mais elástico — as mensagens da NPM vindas da comunidade internacional bastante altamente "editadas" para se adaptarem melhor a algumas das virtudes nórdicas mais tradicionais (Christensen e Laegreid, 1998).

Poderíamos seguir multiplicando essas referências, mas elas provavelmente não nos aproximarão muito mais de um julgamento final a respeito das transformações sistêmicas (Bouckaert, 2000). Seria preciso uma dose de profundo ceticismo para não aceitar o fato de que houve tanto uma mudança estrutural quanto uma evolução cultural naqueles países que deram mais impulso às idéias da $N P M$ - Austrália, Nova Zelândia e Reino Unido. No entanto, mesmo nesses países, fortes elementos de continuidade podem ser identificados e - o que é talvez mais interessante - 15 anos ou mais de reforma pouco colaboraram em termos de estabilidade ou satisfação. Se existe uma nova cultura, não está claro o 
que ela é, ou quem a defende totalmente e quem simplesmente balbucia a retórica e espera pela próxima transformação da moda. Aqueles países parecem quase viciados em reforma administrativa. $\mathrm{O}$ mesmo acontece, de forma menos estrutural e mais voltada para processos, nos Estados Unidos. Em outros lugares, é pouco provável que o termo "transformação" seja realmente justificável. A mudança negociada, seja incremental ou gradual, tem sido a norma na Alemanha, nos Países Baixos e nos Estados nórdicos. Mudanças maiores aconteceram na França, mas os franceses seguramente resistiriam se sugeríssemos que eles têm seguido o modelo da NPM.

\section{Reflexões}

Talvez o fato mais marcante a respeito da $N P M$, na prática, tenha sido o amadorismo dos seus proponentes no seu próprio campo de desempenho. Em teoria, a NPM está totalmente ligada à melhoria do desempenho - fazer os governos mais conscientes em relação a custos, eficientes, eficazes, compreensivos, voltados à satisfação do cliente, flexíveis e transparentes. Na prática, porém, os passos dados para verificar se realmente houve melhoria no desempenho foram quase sempre "muito pequenos, muito atrasados" e muito tímidos em termos de independência.

Há aqui uma falta de reflexividade — os reformistas pregam a orientação por desempenho, mas poucas vezes aplicaram a exigência a si próprios. É claro que fazê-lo teria sido difícil. Como o presente texto torna evidente, os problemas metodológicos e práticos com os quais se confrontam os pretensos avaliadores são consideráveis. Todavia, ao mesmo tempo parece claro que teria sido perfeitamente possível realizar mais análises do que realmente se tentou. O governo do Reino Unido poderia ter realizado uma avaliação sobre a tentativa de introduzir um mercado interno em uma das maiores organizações britânicas — o Serviço Nacional de Saúde - mas não o fez. Os governos neozelandeses da metade e do fim da década de 80 poderiam ter preparado avaliações sistemáticas sobre suas reformas organizacionais radicais, mas não o fizeram. O primeiroministro canadense do período 1984-1993, o Sr. Mulroney, poderia ter solicitado uma análise independente de suas várias iniciativas gerenciais, mas essa não foi a sua decisão. O governo holandês inaugurou um programa de criação de agências em 1991, mas a análise oficial, realizada seis anos mais tarde com dados quantitativos valiosos, desperdiça completamente uma visível oportunidade de verificar se as promessas de maior eficiência e melhor qualidade de serviços foram realmente cumpridas (Ministerie van Financien, 1998). Naqueles casos em que foram realizadas análises 
independentes, suas evidências revelam ambigüidades e lacunas signi-

ficativas (Auditor-Geral do Canadá, 1993; Gabinete-Geral de Contabilidade, 1998; Gabinete-Geral de Auditoria, 1998; Pollitt, 1995; Thompson, 2000).

Como fornecer a tal paradoxo — o de um conjunto de reformas orientadas por desempenho que não dispõe de um sistema para conferir seu próprio desempenho - uma explicação? Existem várias possibilidades. Uma é de que tenha havido um complô perverso para esconder do público a natureza real — e desagradável — das mudanças. Essa possibilidade como explicação nos parece pouco provável, pois em diversos países diferentes tipos de regime brincaram com as idéias da $N P M$ para que a ilusão tivesse credibilidade. Outra explicação é a de que a $N P M$ da qual falamos aqui possa ser definida como um tipo de religião - um sistema de crenças baseado na fé, e não deveria, portanto, ser analisada; embora ela fosse um conjunto de conhecimentos científicos sujeito a testes de veracidade. Esta talvez seja uma interpretação mais persuasiva. Ela nos levaria a procurar pelos mecanismos por meio dos quais a fé se espalha - a identificar os missionários e a tentar encontrar a natureza de seus apelos - ou pelos símbolos que eles usam e os provérbios e histórias que eles contam, e como elas podem ser traduzidas/editadas para adaptar-se localmente às percepções dos grupos dominantes (ver, por exemplo, Hood e Jackson, 1991; Hood, 1998; Premfors, 1998; Williams, 2000; Wright, 1997).

Um aspecto particularmente interessante a respeito da fé na NPM é sua relação com o antigo conjunto de crenças sobre a natureza da democracia liberal. Inicialmente, nos países anglo-saxões pioneiros, durante os anos 80, a conexão parecia pequena. O "gerencialismo" e seus valores parecia ser um empreendimento separado (Hood, 1991; Pollitt, 1993). Durante a década passada, no entanto, pudemos assistir à acomodação dos proponentes da NPM com o vocabulário tradicional da democracia. Hoje em dia, ouvimos falar um bocado de Declaração de Cidadãos, empowerment, inclusão, parceira, soluções em rede e accountability (Clarke, Gewirtz e McLaughlin, 2000). Os governos representam as reformas gerenciais como se estivessem promovendo um papel mais orientador, menos autoritário, mais parceiro, menos exclusivo para si próprios. Nos Estados Unidos, principalmente, foram estabelecidas conexões retóricas explícitas entre a reforma gerencial e a legitimidade do governo aos olhos dos cidadãos. Alguns desses laços citados são altamente questionados (Bok, 1997; Norris, 1999; Pollit e Bouckaert, 2000: 142-146). Ainda assim, fica claro que os que acreditam na NPM sentiram a necessidade de reconhecer o poder perene da "antiga religião" e aliar-se a ela.

Finalmente, uma tal perspectiva antropológica reabre a questão de como a reforma deveria ser avaliada. Se estamos lidando com um conjunto de crenças pré-científicas (a $N P M$ ), então, talvez um ângulo apropriado seja perguntar-se como essa constelação particular de doutrinas ajuda 
seus pregadores e seguidores a proteger seus interesses, reforçar sua reputação e manter a ordem social. Mas os acadêmicos não deveriam esperar que tal investigação fosse simples, visto que sua natureza desafiaria o paradigma da racionalidade instrumental sobre a qual a NPM (e muitas carreiras bem-sucedidas) baseiam-se de modo tão explícito. Segundo os termos da própria NPM, um entendimento tão aprimorado de como suas doutrinas se propagam não traria nenhum "valor agregado" — seria "meramente acadêmico".

\section{Notas}

* Este texto é parte de uma edição sobre avaliação do setor público - Universidade Católica - Leuven, Bélgica. Foi apresentado na conferência organizada por Hellmutt Wolman, "Avaliando a nova gestão pública no mundo", Rio de Janeiro, 13 e 14 de setembro, 2001. Publicação autorizada pelos autores.

1 Nota do tradutor. Segundo a teoria da path-dependent (dependência de caminhos), os processos passados tendem a influenciar o presente. Assim, instituições herdadas condicionam fortemente os caminhos a serem tomados, determinando, inclusive, a persistência de arranjos institucionais pouco eficientes.

2 Nota do tradutor. Double-blind refereeing (avaliação duplamente cega) - para evitar parcialidade na avaliação dos artigos, é corrente as revistas e conferências que os recebem terem uma política de avaliação cega. $\mathrm{O}$ artigo é enviado em duas partes: normalmente, uma primeira página que contém o título do artigo, o nome e filiação do(s) autor(es) e o resumo; e uma segunda parte que contém o artigo completo, mas com o nome e filiação dos autores removidos. A primeira parte é guardada pelos organizadores e só a segunda parte é enviada aos avaliadores, membros conceituados da própria comunidade científica, que os examinam criticamente e anonimamente. Esta forma de avaliação se chama duplamente cega porque nem os avaliadores sabem quem são os autores, nem os autores sabem quem são os avaliadores.

3 Nota do tradutor. Gold standard test (padrão-ouro) - teste definitivo, que utiliza métodos inquestionáveis, para determinar a verdade.

4 Nota do tradutor. Estruturas que oferecem uma ampla variedade de serviços, para comodidade do cliente.

5 Nota do tradutor. Organizações administrativas que operam de forma independente mas apóiam o governo (formada pelas iniciais de "quasi-autonomous, non-governmental organization"). 


\section{Referências bibliográficas}

Aucoin, P., Savoie, D. (1998), Program Review: lessons for strategic change in government. Ottawa: Canadian Centre for Management Development.

Auditor General of Canada. (1993), "Canada's public service reform, and lessons learned from selective jurisdictions". Report, cap. 6, Ottawa: Auditor General of Canada.

BoK, D. (1997), "Measuring the performance of government", in Nye, J., Zelikow, P., KING, D. (eds.), Why people don't trust government. Cambridge, Mass.: Harvard University Press.

BorIns, S. (1998), Innovating with integrity: how local heroes are transforming American government. Washington DC: Georgetown University Press.

Boston, J., Martin, J., Pallot, J., Walsh, P. (1996), Public management: the New Zealand model. Auckland: Oxford University Press.

BoucKAERT, G. (1995). "Charters as frameworks for awarding quality: the Belgian, British and French experience", in Hill Klages, H. (eds.), Trends in public sector renewal: recent developments and concepts in awarding excellence. Europaischer Verlag der Wissenschaften, Beitrage zur Poliyikwissenschaft, Band 58, Frankfurt am Main, Peter Lang.

. (2000), "techniques de modernization et modernization des techniques: evaluer la modernisation de la gestion publique", RouBAn, L. (ed.), Le service publique en devenir. Paris: L'Harmattan.

. (2001), "Pride and performance in public service: some patterns of analysis", International Review of Administrative Sciences, p. 9-20 (67).

Bouckaert, G. , Ormond, D., Peters, G. (2000), A potential agenda for Finland, Helsinki, Ministry of Finance, Research Report no 8 .

Bouckaert, G., Timsit, G. (2000), Administrations and globalizations. Brussels: International Institute of Administrative Sciences.

Bourgon, J. (1998), Fifth annual report to the prime minister on the public service of Canada. Ottawa: Privy Council Office.

Boyne, G. (1998), "Bureaucratic theory meets reality: public choice and contracting" Public Administration Review. Novembro/dezembro, p. 474-484, 58: 6.

BRumby, J., Edmonds, P., HonEYFIELD, K. (1996), Effects of public sector financial reform (FMR) in New Zealand. Paper presented to the Australasian Evaluation Society Conference, 30 de agosto.

Brunsson, N. (1989), The organization of hypocrisy: talk, decisions and actions in organizations. Chichester: John Wiley.

Budget Department. (1997), Public sector productivity in Sweden. Stockholm: Budget Department, Swedish Ministry of Finance, v. 3

Cabinet OfFice. (2000), Adding in up; improving analysis and modelling in central government. London: Performance and Innovation Unit, Cabinet Office.

CAmpBell, D., Stanley, J. (1963), Experimental and quasi-experimental evaluations in social research. Chicago: Rand McNally.

Chancellor of the Duchy of LANCASter. (1997), Next Steps: agencies in government: review 1996. Cm 3579, London: The Stationary Office.

Christensen, T., LAEGREID, P. (1998), “Administrative reform policy: the case of Norway". International Review of Administrative Sciences, p. 457-475 (64).

Clarke, J., Gewirtz, S., McLaughlin, E. (eds.). (2000), New managerialism, new welfare?. Londres: Sage. 

Trust.

Davies, H., Nutley, S., Smith, C. (eds.). (2000), What works? Evidence-based policy and practice in public services. Bristol: Policy Press.

DerLIEN, H-U. (1998), From administrative reform to administrative modernization. Bamberg: Verwaltungswissenschaftlichte, Beitrage 33.

Dorrell, S. (1993), Public sector change is a world-wide movement, discurso do Financial Secretary to the Treasury, Stephen Dorrel, ao Chartered Institute of Public Finance and Accountancy. Londres, 23 de setembro.

Elster, J. (1978), Logic and society: contradictions and possible worlds. Nova York: Wiley.

Escott, K., Whitfield, D. (1995), The gender impact of CCT in local government. Manchester: Equal Opportunities Commission.

Furniss, J., NutLEY, S. (2000), "Implementing what works with offenders - the Effective Practice Initiative". Public Money and Management, outubro/dezembro, p. $23-28$ (20:4).

General Accounting Office. (1997), Performance budgeting; past initiatives offer insights for GPRA implementation. Washington DC: GAO/AIMD-97-46, março.

. (1998), The results Act: observations on the Department of State's Fiscal year 1999 Annual Performance Plan. Washington DC: GAO/NSIAD-98-210R.

GORE, A. (1996), The best-kept secrets in government: a report to President Bill Clinton. Washington DC: US Government Printing Office, National Performance Review.

Guyomarch, A. (1999), “'Public service', 'public management' and the modernization of French public administration". Public Administration, p. 171-193 (77:1).

Harrison, S. (1998), 'The politics of evidence-based medicine in the UK'; Policy and Politics, p. 15-31 (26:1).

Her Majesty's Inspectorate of Probation. (1998), Strategies for effective offender supervision: report of the HMIP what works project. Londres: Home Office.

HolKeri, K., Summa, H. (1996), Contemporary developments in performance management: evaluation of public management reforms in Finland: from ad hoc studies to a programmatic approach. Paper presented to PUMA/OECD. Paris, 4 e 5 de novembro.

Hood, C. (1991), "A public management for all seasons". Public Administration, Primavera, p. 3-19 (69:1).

. (1998), The art of the state; culture, rhetoric ad public management. Oxford: Oxford University Press.

Hood, C., JACKson, M. (1991), Administrative argument. Aldershot: Dartmouth.

Hupe, P., Meiss, L. (2000), Hybrid governance. The Hague, Social and Cultural Planning Office.

Joss, R., Kogan, M. (1995), Advancing quality: Total Quality Management in the national Health Service. Buckingham: Open University Press.

KETTL, D. (2000), The global public management revolution: a report on the transformation of governance. Washington DC: Brookings Institution.

KICKERT, W. (2001), Public management reforms in the Netherlands: social reconstruction of reform ideas and underlying frames of reference. Delft: Eburon.

LAEGREID, P., RoNESS, P. (1999), “Administrative reform as organized attention”, in EgEBERG, M., LAEgRID, P. (eds.), Organizing political institutions: essays for Johan P. Olsen. Oslo: Scandinavian University Press.

Lane, J-E. (2000), New Public Management. London: Routledge.

LOEFFLER, E. (1995), The modernization of the public sector in an international perspective: concepts and methods of awarding and assessing quality in the public sector in OECD countries. Speyer Forschungsberichte 151, Speyer, Forschungsberichte fur Offenlichte Verwaltung. 
Lowndes, V., Skelcher, C. (1998), “The dynamics of multi-organizational partnerships: an analysis of changing modes of governance". Public Administration, Summer, p. 313-334 (76:2).

MAAS, G., VAn NisPen, F. (1999), "The quest for a leaner, not a meaner government". Research in Public Amdinistration, p. 63-86 (5).

MEYER; GuPTA. (1994), “The performance paradox". Research in Organizational Behavior, p. 309-369 (16).

Micheletti, M. (2000), "End of big government: is it happening in the Nordic countries?". Governance, abril, p. 265-278 (13:2).

MiNISTERIE VAN FinANCIEN. (1998), Verder met resultaat: het agentscapsmodel 1991-1997. Den Haag: Ministry of Finance.

Murray, R. (1998), Productivity as a tool for evaluation of public management reform. Paper presented to the European Evaluation Society Conference. Rome, 29-31 de outubro.

National Audit Office. (1995), The Meteorological Office: evaluation of performance, HC693, 25 de agosto. Londres: HMSO.

. (1998), Benefits Agency: performance measurement, HC952, 25 de julho. Londres: The Stationery Office.

. (1999), Government on the web, HC87, 15 de dezembro. Londres:

The Stationery Office, .

NoRris, P. (ed.). (1999), Critical citizens: global support for democratic governance. Oxford: Oxford University Press.

OECD. (1993), Managing with market-type mechanisms. Paris: PUMA/OECD. Paris: PUMA/OECD.

(1997) In search of results: performance management practices.

Olsen, J., Peters, G. (eds.). (1996), Lessons from experience: experiential learning in administrative reform in eight democracies. Oslo: Scandinavian University Press.

Osborne, D., Gaebler, T. (1992), Reinventing Government: how the entrepreneurial spirit is transforming the public sector. Reading, Mass: Adison Wesley.

Packwood, T., Pollitt, C., Roberts, S. (1998), "Good medicine? A case study of business process re-engineering in a hospital”. Policy and Politics, outubro, p. $401-415$ (26:4).

Pawson, R., Tilley, N. (1997), Realistic evaluation. Londres: Sage.

Peterson, M. (2000), "The fate of 'big government' in the United States: not over but undermined?". Governance, abril, p. 251-264 (13:2).

Pierson, P. (2000), "Increasing returns, path dependence and the study of politcs". American Political Science Review, p. 251-267 (94:2).

Pollit, C. (1993), Managerialism and the public services: cuts or cultural changes? Oxford: Blackwell, $2^{\mathrm{a}}$ edição.

(1994), "The Citizen's Charter: a preliminary analysis". Public Money and Management, p. 1-5 (14:2). (1995), "Justifacantion by work or by faith? Evaluating the New public Management". Evaluation, outubro, p.133-154 (1:2).

. (2000), "How do we know how good public services are?", in Peters, G., SAvore, D. (eds.), Governance in the $21^{d}$ century: revitalizing the public service. Montreal and Kingston, Canadian Centre for management Development and McGillQueen's University Press, p. 119-152 .

. (2001) "Clarifying convergence: striking similarities and durable differences in public management reform". Public Management Review, p. 1-22 (3:4).

Pollt, C., BoucKaert, G. (2000), Public management reform: a comparative analysis. Oxford: Oxford University Press. 
Pollit, C., et al. (forthcoming), "Agency fever? analysis of an intenational policy fashion". Journal of comparative Policy Analysis.

PremFors, R. (1998), "Re-shaping the democratic state: Swedish experiences in a comparative perspective". Public Administration, Primavera, p. 141-159 (76:1).

Prime Minister and Minister for the Cabinet Office. (1999), Modernising government. $\mathrm{Cm}$ 413, London: The Stationary Office.

Rouban, L. (1995), "The civil service culture and administrative reform”, in PETERs, B.G., SAvole, D. (eds.), Governance in a changing enviroment. Montreal and Kingston: Canadian Centre for management Development and McGill-Queen's University Press, p. 23-54.

SAhlin-Andersson, K. (1996), "Imitating by editing success: the construction of organizational fields", in CZARnIAWsKa, B., SEVon, G. (eds.), Translating organizational change. Berlin: de Gruyter, p. 69-92.

SAvoIE, D. (1994), Thatcher, Reagan and Mulroney: in search of a new bureaucracy. Toronto: University of Toronto Press.

Schiavo, L. (2000), "Quality standards in the public sector; differences between Italy and the UK in the Citizen's Charter initiatives". Public Administration, p. 679-698 (78:3).

Shadish, W., CooK, T., Leviton, L. (1991), Foudantions of program evaluation. London: Sage.

SHARMAN, Lord. (2001), Holding to account; the review of audit and accountability for central government. Report by Lord Sharman of Redlynch. London, H.M.: Treasury, fevereiro.

SHORtell, et al. (1995), "Assessing the impact of continuous quality improvement/total quality management: concept versus implementation". Health Services Research, p. 377-401 (30:2).

SмIтH, P. (1996), "On the unintended consequences of publishing performances data in the public sector". International Journal of Public Administration, p. 277-305 (18:2/3).

SIGMA. (1999), European principals for public adminstration, SIGMA papers 27. CCNM/ SIGMA/PUMA(99)44/REV1. Paris: OECD/SIGMA/PUMA.

Steering Group. (1991), Review of state sector reform. Auckland, 29 de novembro.

ТАLвот, С. (1996), Ministers and agencies: control, performance and accountability. London: CIPFA.

Task Force on Management Improvement. (1992), The Australian public Service reformed: an evaluation of decade of management reform. Canberra: Management Advisory Board, AGPS.

Thompson, J. (2000), "Reinvention as reform; assessing the National Performance Review”. Public Administration Review, novembro/dezembro, p. 508-521 (60:6).

Williams, D. (2000), "Reinventing the proverbs of government". Public Administration Review, novembro/dezembro, p. 522-534 (60:6).

Wollmanh, H. (1997), "Modernization of the public sector and public administration in the Federal Republic of Germany: (molsty) a story of fragmented incrementalism", in Muramatsu, M., Naschold, F. (eds.), State and administration in Japan and Germany: a comparative perspective on continuity and change. Berlin, de Gruyter, p. 79-103.

Wright, V. (1997), “The paradoxes of administrative reform", in KicKERT, W. (ed.), Public management and administrative reform in Western Europe. Cheltenham: Edward Elgar, p. 7-13. 


\section{Avaliando reformas da gestão pública: uma perspectiva internacional Christopher Pollitt e Geert Bouckaert}

Avaliar as reformas da gestão pública numa perspectiva internacional é um exercício científico difícil e problemático. Cinco problemas parecem emergir: a unidade de análise para uma comparação internacional é menos óbvia do que parece. Níveis de governo são diferentes de setores e de instrumentos e processos específicos. A unidade de sentido é o segundo problema, pois pode ser que uma agência não seja uma agência. A ausência e a qualidade dos dados, além das séries temporais constituem outro conjunto de problemas. A multiplicidade de critérios para se definir a reforma e a imponderabilidade da mudança são um outro problema metodológico. Em todo caso, é possível desenhar um quadro rústico e classicar os esforços de reforma em termos de quatro estratégias principais (4 Ms): manter, modernizar, "mercadificar" e minimizar. Isto nos permite falar de "resultados" mesmo se há uma falta de reflexividade num contexto de paradoxos.

\section{Evaluando las Reformas de la Gestión Pública: una perspectiva internacional Christopher Pollitt y Geert Bouckaert}

Evaluar las reformas de la gestión pública en una perspectiva internacional es un exercício científico difícil y problemático. Cinco problemas parecen emergir: la unidad de análisis para una comparación internacional es menos óbvia que parece. Niveles de gobierno son diferentes de sectores y de instrumentos y procesos específicos. La unidad de sentido es el segundo problema, pues que una agencia puede no ser exactamente una agencia. La ausencia y la calidad de los datos, además de las séries temporales constituyen otro conjunto de problemas. La multiplicidad de criterios para se definir la reforma, así como la elusión del cambio son un outro problema metodológico. De toda manera, es posible dibujar un cuadro rústico y classificar los esfuerzos de reforma en términos de cuatro estrategias principales (4 Ms): mantener, modernizar, "mercadizar" y minimizar. Eso nos permite hablar de "resultados" aunque falte reflexividad en un contexto de paradojas.

\section{Evaluating public management reforms: an international perspective \\ Christopher Pollitt and Geert Bouckaert}

Evaluation public management reforms in an international perspective is a difficult and problematic scientific exercise. Five problems seem to emerge. The unit of analysis for an international comparison is less obvious as it seems. Levels of government are different from sectors and from specific instruments and processes. The unit of meaning is a second problem since, e.g. an agency is not an agency. The lack and the quality of data, and the time series are another set of problems. The multiplicity of criteria to define reform and the elusiveness of change are other methodological problems. Nevertheless, it is possible to draw a big picture and to classify reform efforts in terms of four main strategies (4M's): maintain, modernize, marketize and minimize. This allows to talk about 'results' even if there is a lack of reflexivity and in a context of paradoxes.
Revista do

Serviço

Público

Ano 53

Número 3

Jul-Set 2002
Christopher Pollitt é PhD pela London School of Economics and Political Science e professor na Erasmus Universiteit Rotterdam, Holanda.

Geert Bouckaert é diretor do Instituut voor de Overheid da Katholiek Universiteit Leuven, Bélgica e membro do comitê de direção do European Group of Public Administration (EGPA).

Contato: pollitt@fsw.eur.nl geert.bouckaert@ $\underline{\text { soc.kuleuven.ac.be }}$ 
